Annales Geophysicae (2003) 21: 151-165 (C) European Geosciences Union 2003

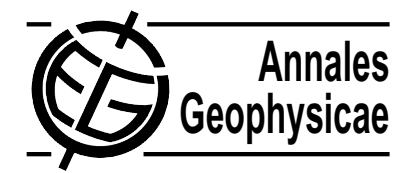

\title{
Observing System Simulation Experiments for the assessment of temperature sampling strategies in the Mediterranean Sea
}

\author{
F. Raicich and A. Rampazzo \\ CNR, Istituto Sperimentale Talassografico, viale Romolo Gessi 2, I-34123 Trieste, Italy
}

Received: 23 August 2001 - Revised: 22 January 2002 - Accepted: 29 January 2002

\begin{abstract}
For the first time in the Mediterranean Sea various temperature sampling strategies are studied and compared to each other by means of the Observing System Simulation Experiment technique. Their usefulness in the framework of the Mediterranean Forecasting System (MFS) is assessed by quantifying their impact in a Mediterranean General Circulation Model in numerical twin experiments via univariate data assimilation of temperature profiles in summer and winter conditions. Data assimilation is performed by means of the optimal interpolation algorithm implemented in the SOFA (System for Ocean Forecasting and Analysis) code.
\end{abstract}

The sampling strategies studied here include various combinations of eXpendable BathyThermograph (XBT) profiles collected along Volunteer Observing Ship (VOS) tracks, Airborne XBTs (AXBTs) and sea surface temperatures. The actual sampling strategy adopted in the MFS Pilot Project during the Targeted Operational Period (TOP, winter-spring 2000 ) is also studied.

The data impact is quantified by the error reduction relative to the free run. The most effective sampling strategies determine $25-40 \%$ error reduction, depending on the season, the geographic area and the depth range. A qualitative relationship can be recognized in terms of the spread of information from the data positions, between basin circulation features and spatial patterns of the error reduction fields, as a function of different spatial and seasonal characteristics of the dynamics. The largest error reductions are observed when samplings are characterized by extensive spatial coverages, as in the cases of AXBTs and the combination of XBTs and surface temperatures. The sampling strategy adopted during the TOP is characterized by little impact, as a consequence of a sampling frequency that is too low.

Key words. Oceanography: general (marginal and semienclosed seas; numerical modelling)

Correspondence to: F. Raicich (fabio.raicich@itt.ts.cnr.it)

\section{Introduction}

The Mediterranean Sea is a basin largely dominated by open ocean processes whose influence can be observed also in the coastal/shelf circulation. The large-scale general circulation is composed of intense coastal/boundary currents and gyres with large seasonal and interannual variability (Millot, 1987; Robinson et al., 1991). The horizontal structure of the circulation is associated with vertical motions connected to the formation of deep and intermediate water masses. The major current structures and the water-mass formation processes are driven by the atmospheric forcing, namely wind stress and heat fluxes.

The overall objective of the Mediterranean Forecasting System is to explore, model and quantify the potential predictability of the marine ecosystem variability (Pinardi and Flemming, 1998), which requires, among other elements, the support of an observational system to monitor the relevant parameters in the water column. The time and space coverage provided by the oceanographic data sets is generally limited, particularly if compared to meteorological data sets, as a consequence of logistic problems and the high cost of data collection. The optimization of data sampling strategies is, therefore, a desirable task, although, in general, difficult to achieve, with the details depending on the scientific objective of data collection and unavoidable external constraints (e.g. ship availability).

Among the components of the observing system (Pinardi and Flemming, 1998), the Mediterranean Forecasting System Pilot Project (MFSPP) includes a programme of eXpendable BathyThermograph (XBT) profiles collection; XBTs are routinely deployed along the Volunteer Observing Ship (VOS) tracks which form the network described in MFSVOS Group (2003) and the data is subsequently assimilated into a Mediterranean General Circulation Model (GCM) for the purpose of forecasting (Demirov et al., 2003). In the absence of previous experiences in the Mediterranean, the VOS track network design is based on the scientific knowledge of the basin circulation, although it is constrained by logistic 
Table 1. Comparison of temperature errors $\left({ }^{\circ} \mathrm{C}\right)$ in the assimilation run, computed for the whole basin and layer L1 using sampling strategy T7, with different initial conditions. See text for the explanation of symbols

\begin{tabular}{ccccccc}
\hline \multicolumn{7}{c}{ Initialization: 1 February } \\
\multicolumn{1}{c}{1999} & \multicolumn{2}{c}{1998} & \multicolumn{2}{c}{1997} \\
& Initial & Final & Initial & Final & Initial & Final \\
\hline $\mathrm{rms}$ & 0.61 & 0.37 & 0.84 & 0.46 & 1.04 & 0.67 \\
$\mathrm{rms}_{m}$ & 0.14 & 0.10 & 0.45 & 0.24 & 0.85 & 0.56 \\
$\sigma$ & 0.59 & 0.36 & 0.63 & 0.37 & 0.57 & 0.32 \\
\hline
\end{tabular}

limitations. The present exploratory study, applied for the first time to the Mediterranean Sea, does not have the objective of the observing system optimization, but rather its aim is to assess and compare the usefulness of the existing and other realistic temperature sampling strategies, mainly involving XBTs. The assessment of each sampling strategy is obtained by studying the impact of temperature data assimilation into the Mediterranean GCM by means of Observing System Simulation Experiments (OSSE) techniques.

The OSSE approach was first adopted in the meteorological community to assess the impact of "future" (i.e. not available from current instruments) observations, in order to improve numerical weather predictions (see the review paper by Arnold and Dey, 1986); in addition, OSSEs have been also performed to assess trade-offs in the design of observing systems and observing networks (e.g. Rohaly and $\mathrm{Kr}$ ishnamurti, 1993). In oceanography, examples of past studies on sampling strategy optimization, or assessment towards optimization, involve satellite tracks (Kindle, 1986), ship-ofopportunity tracks (Bennett, 1990), acoustic tomography arrays (Barth and Wunsch, 1990), drifters (Hernandez et al., 1994), and mooring arrays (Hackert et al., 1998).

In the next section, the methods will be described and in Sect. 3, the sampling strategies will be summarized. In Sect. 4, the results of the sampling strategy assessment will be outlined and discussed, while in Sect. 5, we will make some remarks on the relationship between the characteristics of the basin circulation and the spatial patterns of data impact. Section 6 will present the conclusions.

\section{Methods}

OSSEs consist of identical twin experiments, a widely used technique to assess the impact of data assimilation, in which data selected from one model run is assimilated into another run of the same model with different initial conditions. The convergence of the second run towards the first, defined as the "truth", can be measured to quantify the data assimilation effectiveness in driving the model with "wrong" initial conditions towards the truth. Each twin experiment includes the following simulations:

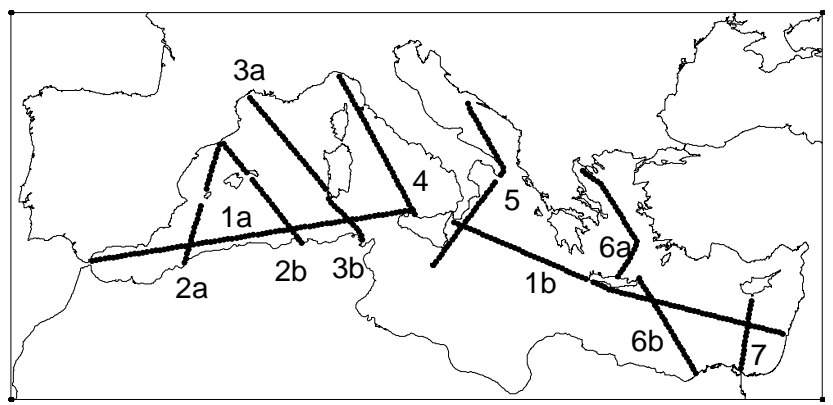

Fig. 1. Design of the VOS track network.

- Control run, which represents the "true" ocean and provides the simulated temperature data to be used in the assimilation;

- Assimilation run, with different initial conditions from the control run and including the assimilation of temperature data extracted from the control run;

- Free run, initialized as the assimilation run but without data assimilation.

All runs are driven by the same external forcing.

The Mediterranean GCM used for the simulations is an eddy-resolving version of the Geophysical Fluid Dynamics Laboratory MOM-1 (Pacanowski et al., 1990), having $1 / 8^{\circ} \times 1 / 8^{\circ}$ horizontal resolution and 31 vertical levels $(5$, $15,30,50,70,90,120,160,200,240,280,320,360,400$, $440,480,520,580,660,775,925,1150,1450,1750,2050$, $2350,2650,2950,3250,3550$ and $3850 \mathrm{~m})$. Its implementation in the MFSPP includes interactive surface heat flux calculation, surface salinity relaxation and constant vertical diffusion. Gibraltar Strait is open on a $3^{\circ} \times 3^{\circ}$ Atlantic box. More model details are described in Korres et al. (2000) and Demirov et al. (2003). The model is forced by ECMWF 6hourly operational analyses of $10 \mathrm{~m}$-wind and $2 \mathrm{~m}$-air temperature, also used in the surface heat flux calculation. Surface salinity is relaxed to the MED6 climatology (Brasseur et al, 1996; Fichaut et al., 1998).

Data assimilation is performed by means of the reducedorder optimal interpolation technique, based on the scheme by Derber and Rosati (1989) and implemented in the SOFA (System for Ocean Forecasting and Analysis) code (De Mey 1994, 1997; De Mey and Benkiran, 2002). The setup adopted for the present work allows for univariate assimilation of temperature profiles. Data assimilation is performed on the basis of 7-day cycles, involving only past data (filter mode) within a 7-day window; corrections are applied to the model temperature at the end of each cycle. The data error covariance radius is $10^{-6} \mathrm{~km}$ and the e-folding time is $10^{-6}$ days, implying that the data are uncorrelated with each other. The forecast error covariance radius is $45 \mathrm{~km}$ and e-folding time is 105 days, which results in giving all the data within the 7 day window essentially the same weight in the assimilation process. These parameters are based on the setup adopted in the MFSPP forecasting experiments (Demirov et al., 2003). 


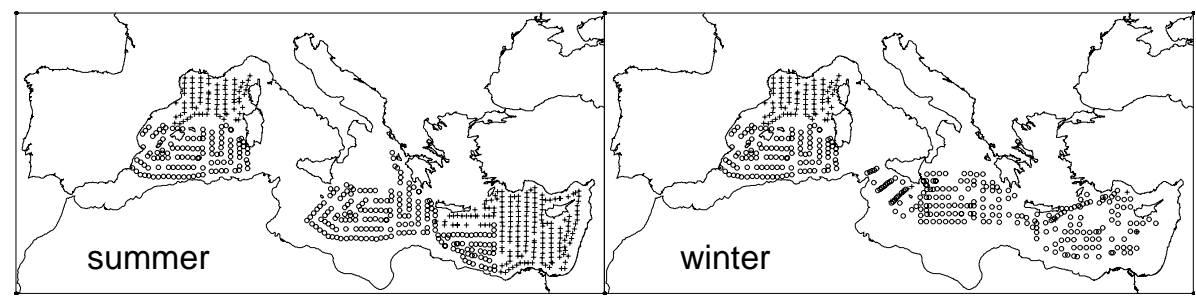

Fig. 2. Positions of AXBT deployments included in the AXT7 summer and winter sampling strategies. Deployments in the first week are indicated by circles and those in the second week by "plus" signs.

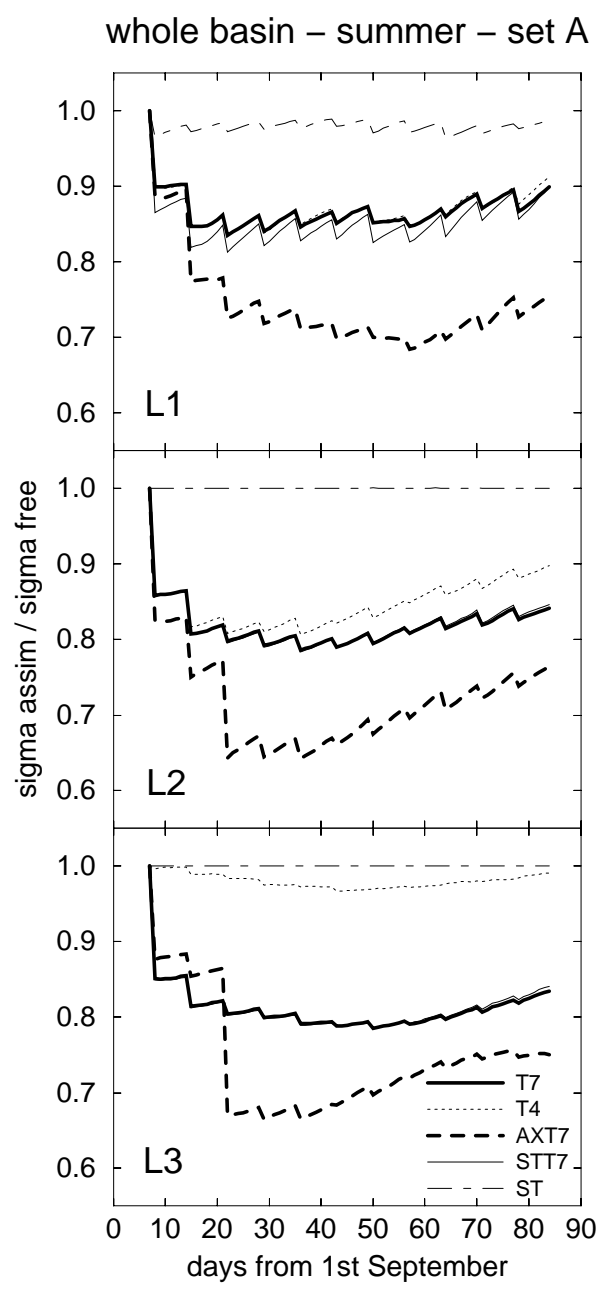

Fig. 3. Time series of temperature relative errors for the whole basin in the summer OSSEs with sampling strategies of set A. L1 indicates the surface layer, L2 the intermediate layer and L3 the deep layer.

OSSEs are made in two seasonal configurations which are here defined as "summer" and "winter", according to the initial state of the ocean, and each experiment lasts for 84 days, corresponding to 12 assimilation cycles. The summer OSSEs are initialized on 1 September 1999, and end on 23 November 1999, while the winter OSSEs cover the period 1 February - 24 April 2000. The free run and assimilation run are initialized on 1 September 1998 (summer) and 1 February 1999

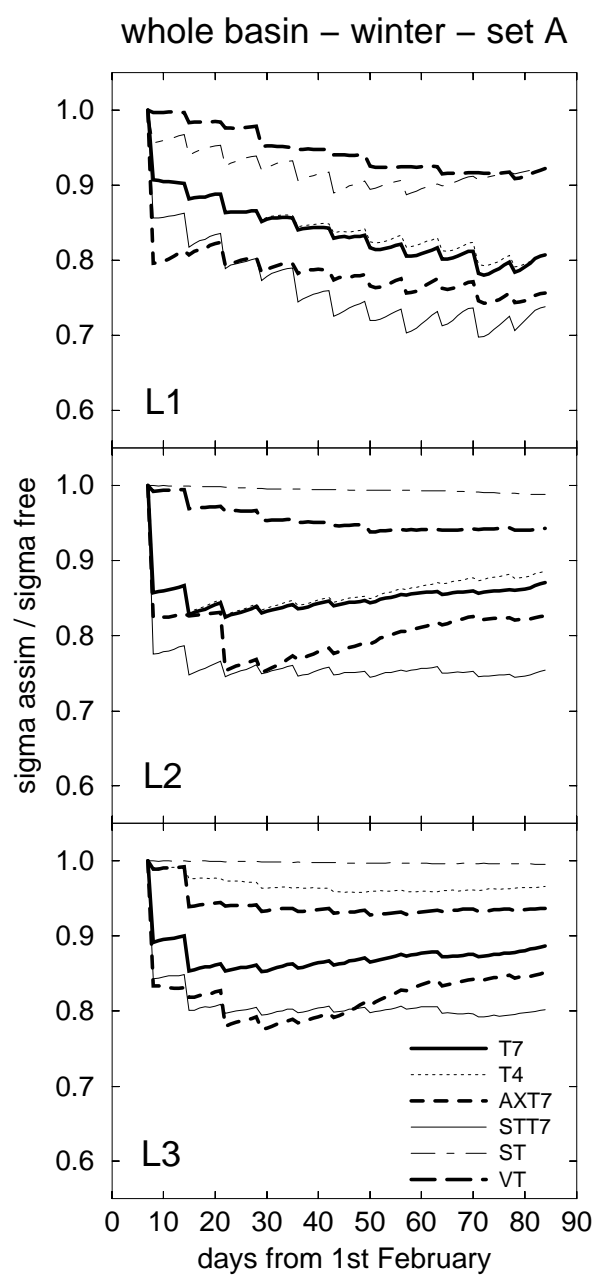

Fig. 4. As Fig. 3 for winter OSSEs.

(winter). All the initialization fields are taken from an interannual simulation without data assimilation that was started in 1993 and forced by ECMWF 6-hourly analyses.

The convergence of assimilation run towards the control run is assessed by means of standard deviations of the differences between the two runs (Miyakoda et al., 1969). The convergence of the free run towards the control run, assessed in the same way, is used for reference, since it shows the ability of the model to converge towards the control run due to the atmospheric forcing only. Standard deviations are computed for temperature, salinity, density and barotropic stream function. It should be noted that only temperature is di- 
Table 2. Summary of the sampling strategies studied in this work. Experiments with all strategies are performed in summer and winter conditions except VT, studied only in winter

\begin{tabular}{cccl}
\hline $\begin{array}{c}\text { Sampling } \\
\text { strategy }\end{array}$ & $\begin{array}{c}\text { Data } \\
\text { type }\end{array}$ & $\begin{array}{c}\text { Maximum } \\
\text { depth }(\mathrm{m})\end{array}$ & Spatial and time coverages \\
\hline VT & XBT & 775 & See Fig. 1 and Table 3. \\
T4 & XBT & 400 & See Fig. 1. Track 1 fortnightly, tracks 2-7 weekly for all 12 weeks. \\
T7 & XBT & 775 & As T4. \\
T7-n & XBT & 775 & As T4 except track n $(\mathrm{n}=1, \ldots, 7)$. \\
AXT7 & 1) AXBT & 775 & See Fig. 2 for weeks 1-2. \\
& 2) XBT & 775 & As T4 for weeks 3-12. \\
ST & SST & 5 & Once daily for all 12 weeks. See also Table 4. \\
STT7 & 1) SST & 5 & As ST. \\
& 2) XBT & 775 & As T4. \\
\hline
\end{tabular}

rectly affected by data assimilation, since univariate assimilation does not allow one to project temperature corrections onto the other variables, whose changes are, therefore, due to the model dynamics only. Standard deviations are computed for the whole basin, the western Mediterranean (which comprises Alboran Sea, Algerian Current region, Gulf of Lions, Tyrrhenian Sea and north Sicily Channel) and eastern Mediterranean (comprising south Sicily Channel, Adriatic Sea, Ionian Sea, Aegean Sea and Levantine Basin), and some depth ranges, defined by taking into account the typical vertical structure of the Mediterranean water-mass distribution. Three layers are defined as follows: L1, which includes 10 model levels from 5 to $240 \mathrm{~m}$ depth and roughly corresponds to the surface waters; L2, including 4 levels from 280 to $400 \mathrm{~m}$ and approximately corresponding to the Levantine Intermediate Water (LIW) layer (e.g. Robinson et al., 1991); L3, including 17 levels from $440 \mathrm{~m}$ to the sea bottom. OSSEs use the same GCM setup as the forecasting work and mainly focus on the whole Mediterranean basin; moreover, no regional optimization of the data assimilation parameters has been made. For these reasons, we perform the sampling strategy analysis only on large regions, namely the whole basin and the western and eastern subbasins, and not on smaller regions.

Standard deviations, which are computed using the anomalies relative to the spatial means, are adopted instead of root-mean-squared differences, computed with the full fields, since they appear to be more sensitive to data assimilation. If we consider two n-dimensional samples, $a_{i}$ and $b_{i}$, let $m_{a}$ and $m_{b}$ be their arithmetic means over a given domain and $a_{i}^{\prime}=a_{i}-m_{a}$ and $b_{i}^{\prime}=b_{i}-m_{b}$ the anomalies relative to those means. The relationship between the rootmean-squared difference $r m s$ and the standard deviation $\sigma$ is given by the equation $r m s^{2}=r m s_{m}^{2}+\sigma^{2}$, where

$r m s^{2}=\frac{1}{n} \sum_{i=1}^{n}\left(a_{i}-b_{i}\right)^{2}$

$r m s_{m}^{2}=\left(m_{a}-m_{b}\right)^{2}$ $\sigma^{2}=\frac{1}{n} \sum_{i=1}^{n}\left(a_{i}^{\prime}-b_{i}^{\prime}\right)^{2}$

Thus, $r m s^{2}$ is the sum of a quantity which is the squared difference between the means $\left(r m s_{m}^{2}\right)$ and one which depends only on the anomalies $\left(\sigma^{2}\right)$. We made experiments with sampling strategy T7 (which will be described in Sect. 3), where the assimilation runs are initialized on 1 February 1997, 1998 and 1999. In such cases, using the symbols adopted above, $a$ represents temperature at a certain model level that is extracted from the assimilation run and $b$ represents the same from the control run; $m_{a}$ and $m_{b}$ are the means of such horizontal fields over the whole Mediterranean Sea. As a result, the choice of the initial conditions mainly affects $r m s_{m}^{2}$, while $\sigma$ is less dependent on the initialization (Table 1). As a consequence, $\sigma$ turns out to be more sensitive to data assimilation than $r m s$ and will, therefore, be adopted here in the experiment analysis. In what follows, $\sigma$ will be denoted simply as the "error".

\section{Sampling strategies}

In this work, we study the following sampling strategies, listed also in Table 2:

- VT: This is the actual sampling strategy of the MFSPP Volunteer Observing Ship programme in the real-time forecasting experiment during the Targeted Operational Period (MFS-VOS Group, 2003). The track network is shown in Fig. 1. Table 3 summarizes the track coverage, week by week, during the period of 1 February -24 April 2000. The maximum depth of XBT data is $775 \mathrm{~m}$.

- T4, T7: The spatial design of these sampling strategies is the same as for VT, and the difference from VT is a regular and more frequent track coverage: tracks 1a and $1 \mathrm{~b}$ are covered once every two weeks (track $1 \mathrm{~b}$ during the odd weeks and track 1a during the even weeks) and tracks $2 \mathrm{a}$ to 7 once a week. The numbers of profiles composing each track are: 77 (track 1a), 82 (track 1b), 
Table 3. VT sampling strategy: numbers of XBTs deployed along each track per week, corresponding to a data assimilation cycle. Dashes mean "zero". The track design is shown in Fig. 1. Track 6a starts in Piraeus instead of Thessaloniki as originally planned

\begin{tabular}{lcccccccccccc}
\hline & \multicolumn{1}{c}{ Week } & \multicolumn{1}{c}{} & & & & & & \\
& 1 & 2 & 3 & 4 & 5 & 6 & 7 & 8 & 9 & 10 & 11 & 12 \\
\hline Track 1a & - & - & - & - & - & - & - & 1 & - & - & - & 1 \\
Track 1b & - & - & - & - & - & - & - & - & - & - & 53 & - \\
Track 2a & - & - & - & - & - & - & - & - & - & - & - & - \\
Track 2b & - & 32 & - & - & - & 24 & 8 & - & - & - & 32 & - \\
Track 3a & 30 & - & 26 & - & 30 & - & 30 & - & 30 & - & 30 & - \\
Track 3b & - & 9 & - & 14 & - & 13 & - & 14 & - & 10 & - & 8 \\
Track 4 & - & 37 & - & 36 & - & 38 & - & 2 & - & 2 & - & - \\
Track 5 & - & 35 & - & 35 & - & 40 & - & 46 & - & 41 & - & 42 \\
Track 6a & - & - & - & 15 & - & - & 18 & - & 16 & - & - & 17 \\
Track 6b & - & - & - & 19 & - & - & 20 & - & 19 & - & - & 22 \\
Track 7 & 16 & 2 & 14 & 3 & 16 & 2 & 14 & 2 & 14 & 4 & 15 & 3 \\
\hline
\end{tabular}

Table 4. Percentage of basin area covered weekly by surface temperature data used in the ST and STT7 sampling strategies. Numbers represent the percentage ratio between the number of $1 / 2^{\circ} \times 1 / 2^{\circ}$ gridpoints with surface temperature observations and the total number of gridpoints

\begin{tabular}{lcccccccccccc}
\hline & \multicolumn{11}{c}{ Week } \\
& 1 & 2 & 3 & 4 & 5 & 6 & 7 & 8 & 9 & 10 & 11 & 12 \\
\hline Summer & 77 & 75 & 57 & 76 & 75 & 53 & 52 & 43 & 59 & 31 & 20 & 8 \\
Winter & 63 & 42 & 51 & 45 & 66 & 58 & 32 & 66 & 38 & 29 & 37 & 51 \\
\hline
\end{tabular}

25 (track 2a), 28 (track 2b), 27 (track 3a), 13 (track 3b), 34 (track 4), 43 (track 5), 30 (track 6a), 26 (track 6b) and 16 (track 7). XBTs are deployed every 12 nautical miles and the times of deployment are computed on the basis of nominal VOS speeds (MFS-VOS Group, 2003). $\mathrm{T} 4$ and $\mathrm{T} 7$ are spatially and temporally equal, the only difference being the fact that T4 involves XBTs operating to a maximum depth of $400 \mathrm{~m}$, while in $\mathrm{T} 7$, the maximum depth is $775 \mathrm{~m}$.

- T7- $n$ (with $n$ varying from 1 to 7): These sampling strategies are identical to T7, except that track $n$ is not included.

- AXT7: This strategy combines the deployment of Airborne eXpendable BathyThermographs (AXBTs) and T7 XBTs. During the first two weeks only AXBTs are deployed, one at each position according to the survey designs shown in Fig. 2, while from week 3 on, only XBTs are involved. In the eastern Mediterranean, the AXBT survey designs are those reported in Horton et al. (1994), using the schemes of December 1991 for the winter OSSE and July 1992 for the summer OSSE. In the western Mediterranean, previous AXBT survey designs are not available; therefore, the adopted design is obtained by transposing Horton's summer survey, the same design being adopted both for summer and winter. The summer survey includes 314 AXBTs in the first week and 261 in the second week, while the winter survey consists of 340 AXBTs in the first week and 89 in the second week.

- ST: This strategy uses sea surface temperature data, represented by temperature at model level 1 ( $5 \mathrm{~m}$ depth) The data coverage is based on the real spatial coverage of AVHRR weekly MCSST data during the OSSEs' periods in summer-autumn 1999 and winter-spring 2000. Data are provided daily, at $12: 00 \mathrm{UTC}$, on a $1 / 2^{\circ} \times 1 / 2^{\circ}$ grid, at the positions where at least 10 observations are available during each week (corresponding to an average of at least one observation per day). Table 4 summarizes the percentage of basin area covered weekly by surface temperature data.

- STT7: This strategy is obtained by combining ST and T7 sampling strategies, therefore using surface temperature and XBT data simultaneously during the whole experiment duration.

We stress that, even when the sampling strategies are based on real data distributions, only the times and positions of the XBT launches are taken from the survey schemes, while the temperature profiles for assimilation are always extracted from the control runs at the appropriate times and positions. Summer and winter OSSEs are performed for all the sampling strategies described above, except VT, for which only 
Table 5. Summer OSSEs: Initial and final errors in the assimilation runs relative to the control run for selected sampling strategies (T7, T4, T7-1, AXT7, STT7) arranged by parameter (temperature, salinity, density, barotropic stream function), basin (whole, western, eastern Mediterranean) and layer (L1, L2, L3)

\begin{tabular}{|c|c|c|c|c|c|c|c|}
\hline & & \multirow[t]{2}{*}{ Initial error } & \multicolumn{5}{|c|}{ Final error } \\
\hline & & & $\mathrm{T} 7$ & $\mathrm{~T} 4$ & T7-1 & AXT7 & STT7 \\
\hline \multicolumn{8}{|c|}{ Temperature $\left({ }^{\circ} \mathrm{C}\right)$} \\
\hline \multirow[t]{3}{*}{ whole basin } & L1 & 0.50 & 0.31 & 0.32 & 0.34 & 0.26 & 0.31 \\
\hline & $\mathrm{L} 2$ & 0.27 & 0.21 & 0.22 & 0.23 & 0.18 & 0.21 \\
\hline & L3 & 0.21 & 0.16 & 0.19 & 0.17 & 0.14 & 0.16 \\
\hline \multirow[t]{3}{*}{ W Med } & L1 & 0.66 & 0.34 & 0.36 & 0.42 & 0.32 & 0.33 \\
\hline & L2 & 0.31 & 0.24 & 0.25 & 0.30 & 0.26 & 0.25 \\
\hline & L3 & 0.18 & 0.14 & 0.17 & 0.17 & 0.14 & 0.14 \\
\hline \multirow[t]{3}{*}{ E Med } & L1 & 0.45 & 0.31 & 0.31 & 0.32 & 0.27 & 0.31 \\
\hline & $\mathrm{L} 2$ & 0.41 & 0.31 & 0.33 & 0.33 & 0.26 & 0.31 \\
\hline & L3 & 0.32 & 0.24 & 0.28 & 0.25 & 0.21 & 0.24 \\
\hline \multicolumn{8}{|l|}{ Salinity (psu) } \\
\hline \multirow[t]{3}{*}{ whole basin } & L1 & 0.18 & 0.13 & 0.13 & 0.14 & 0.14 & 0.13 \\
\hline & L2 & 0.23 & 0.18 & 0.19 & 0.19 & 0.18 & 0.18 \\
\hline & L3 & 0.15 & 0.13 & 0.14 & 0.13 & 0.13 & 0.13 \\
\hline \multirow[t]{3}{*}{ W Med } & L1 & 0.39 & 0.29 & 0.30 & 0.31 & 0.28 & 0.29 \\
\hline & $\mathrm{L} 2$ & 0.41 & 0.32 & 0.34 & 0.35 & 0.31 & 0.32 \\
\hline & L3 & 0.18 & 0.14 & 0.15 & 0.16 & 0.15 & 0.15 \\
\hline \multirow[t]{3}{*}{ E Med } & L1 & 0.17 & 0.12 & 0.12 & 0.12 & 0.14 & 0.12 \\
\hline & $\mathrm{L} 2$ & 0.50 & 0.40 & 0.42 & 0.41 & 0.42 & 0.40 \\
\hline & L3 & 0.35 & 0.30 & 0.32 & 0.30 & 0.31 & 0.30 \\
\hline \multicolumn{8}{|c|}{ Density $\left(\mathrm{kg} \mathrm{m}^{-3}\right)$} \\
\hline \multirow[t]{3}{*}{ whole basin } & L1 & 0.33 & 0.20 & 0.20 & 0.22 & 0.18 & 0.20 \\
\hline & L2 & 0.43 & 0.40 & 0.41 & 0.40 & 0.36 & 0.39 \\
\hline & L3 & 0.19 & 0.21 & 0.19 & 0.21 & 0.22 & 0.23 \\
\hline \multirow[t]{3}{*}{ W Med } & L1 & 0.56 & 0.32 & 0.34 & 0.38 & 0.31 & 0.33 \\
\hline & $\mathrm{L} 2$ & 0.71 & 0.53 & 0.57 & 0.56 & 0.51 & 0.54 \\
\hline & L3 & 0.37 & 0.35 & 0.34 & 0.34 & 0.32 & 0.35 \\
\hline \multirow[t]{3}{*}{ E Med } & L1 & 0.27 & 0.17 & 0.17 & 0.17 & 0.16 & 0.17 \\
\hline & $\mathrm{L} 2$ & 0.38 & 0.39 & 0.40 & 0.39 & 0.35 & 0.38 \\
\hline & L3 & 0.23 & 0.30 & 0.25 & 0.29 & 0.31 & 0.33 \\
\hline \multicolumn{8}{|c|}{ Barotropic stream function (Sv) } \\
\hline whole basin & & 1.04 & 0.97 & 0.96 & 0.96 & 0.95 & 0.98 \\
\hline W Med & & 1.35 & 1.26 & 1.25 & 1.27 & 1.23 & 1.27 \\
\hline E Med & & 0.47 & 0.46 & 0.45 & 0.46 & 0.44 & 0.46 \\
\hline
\end{tabular}

the winter case is studied, corresponding to the Targeted Operational Period.

\section{Sampling strategies assessment and comparison}

Tables 5 and 6 summarize the results obtained in the numerical experiments in the summer and winter configurations, respectively, with selected sampling strategies for the whole Mediterranean basin and for the eastern and western subbasins. Initial and final errors in the assimilation runs relative to the control run are reported as absolute values.

\subsection{Temperature}

Figures 3-8 show temperature relative errors computed on a daily basis for each sampling strategy. The relative error is the ratio between assimilation run error and free run error and allows one to recognize the improvement over the free run achieved by data assimilation. To better visualize the comparisons between different relative error curves, three sets are defined, namely set A, which includes the curves for sampling strategies T7, T4, AXT7, ST, STT7 and VT; set B, including T7, T7-1, T7-2, T7-3 and T7-4; and set C, including T7, T7-1, T7-5, T7-6 and T7-7. Strategies T7 and T7-1 are included in more sets for reference.

All the sampling strategies studied in the experiments lead to improved model performances, i.e. relative error less than 1 , in all layers. Most of the error reduction usually occurs after the first and second assimilation cycles, except for strategy AXT7, where two more assimilation cycles are needed. In the subsequent cycles, relative errors remain almost stable or even tend to increase slightly until the end of the runs, ex- 
Table 6. Winter OSSEs: Initial and final errors in the assimilation runs relative to the control run for selected sampling strategies (T7, T4, T7-1, AXT7, STT7, VT) arranged by parameter (temperature, salinity, density, barotropic stream function), basin (whole, western, eastern Mediterranean) and layer (L1, L2, L3)

\begin{tabular}{|c|c|c|c|c|c|c|c|c|}
\hline & & \multirow[t]{2}{*}{ Initial error } & \multicolumn{5}{|c|}{ Final error } & \multirow[b]{2}{*}{ VT } \\
\hline & & & $\mathrm{T} 7$ & $\mathrm{~T} 4$ & $\mathrm{~T} 7-1$ & AXT7 & STT7 & \\
\hline \multicolumn{9}{|c|}{ Temperature $\left({ }^{\circ} \mathrm{C}\right)$} \\
\hline \multirow[t]{3}{*}{ whole basin } & L1 & 0.40 & 0.24 & 0.24 & 0.26 & 0.22 & 0.21 & 0.27 \\
\hline & L2 & 0.38 & 0.30 & 0.31 & 0.32 & 0.29 & 0.26 & 0.33 \\
\hline & L3 & 0.22 & 0.18 & 0.20 & 0.19 & 0.17 & 0.17 & 0.20 \\
\hline \multirow[t]{3}{*}{ W Med } & L1 & 0.47 & 0.28 & 0.27 & 0.31 & 0.29 & 0.27 & 0.35 \\
\hline & L2 & 0.56 & 0.31 & 0.31 & 0.37 & 0.31 & 0.29 & 0.45 \\
\hline & L3 & 0.28 & 0.21 & 0.25 & 0.23 & 0.20 & 0.18 & 0.25 \\
\hline \multirow[t]{3}{*}{ E Med } & L1 & 0.49 & 0.26 & 0.26 & 0.29 & 0.24 & 0.24 & 0.31 \\
\hline & L2 & 0.52 & 0.38 & 0.39 & 0.42 & 0.37 & 0.38 & 0.42 \\
\hline & L3 & 0.33 & 0.27 & 0.30 & 0.28 & 0.26 & 0.27 & 0.28 \\
\hline \multicolumn{9}{|l|}{ Salinity (psu) } \\
\hline \multirow[t]{3}{*}{ whole basin } & L1 & 0.20 & 0.20 & 0.20 & 0.20 & 0.20 & 0.19 & 0.20 \\
\hline & L2 & 0.22 & 0.23 & 0.23 & 0.23 & 0.22 & 0.22 & 0.23 \\
\hline & L3 & 0.13 & 0.12 & 0.12 & 0.12 & 0.12 & 0.11 & 0.13 \\
\hline \multirow{3}{*}{ W Med } & L1 & 0.36 & 0.38 & 0.38 & 0.39 & 0.37 & 0.37 & 0.39 \\
\hline & L2 & 0.48 & 0.51 & 0.52 & 0.49 & 0.49 & 0.49 & 0.51 \\
\hline & L3 & 0.19 & 0.19 & 0.20 & 0.20 & 0.19 & 0.18 & 0.21 \\
\hline \multirow[t]{3}{*}{ E Med } & L1 & 0.21 & 0.18 & 0.19 & 0.19 & 0.18 & 0.18 & 0.18 \\
\hline & L2 & 0.40 & 0.37 & 0.38 & 0.41 & 0.37 & 0.37 & 0.41 \\
\hline & L3 & 0.33 & 0.28 & 0.31 & 0.31 & 0.29 & 0.28 & 0.30 \\
\hline \multicolumn{9}{|c|}{ Density $\left(\mathrm{kg} \mathrm{m}^{-3}\right)$} \\
\hline \multirow[t]{3}{*}{ whole basin } & L1 & 0.41 & 0.32 & 0.32 & 0.34 & 0.32 & 0.31 & 0.36 \\
\hline & L2 & 0.73 & 0.64 & 0.64 & 0.64 & 0.62 & 0.59 & 0.65 \\
\hline & L3 & 0.29 & 0.30 & 0.29 & 0.27 & 0.30 & 0.27 & 0.28 \\
\hline \multirow[t]{3}{*}{ W Med } & L1 & 0.37 & 0.33 & 0.33 & 0.35 & 0.33 & 0.32 & 0.37 \\
\hline & $\mathrm{L} 2$ & 0.80 & 0.74 & 0.73 & 0.72 & 0.72 & 0.69 & 0.78 \\
\hline & L3 & 0.45 & 0.45 & 0.46 & 0.42 & 0.43 & 0.41 & 0.45 \\
\hline \multirow[t]{3}{*}{ E Med } & L1 & 0.46 & 0.30 & 0.31 & 0.32 & 0.29 & 0.29 & 0.33 \\
\hline & L2 & 0.60 & 0.49 & 0.49 & 0.49 & 0.47 & 0.49 & 0.48 \\
\hline & L3 & 0.29 & 0.31 & 0.28 & 0.27 & 0.31 & 0.31 & 0.26 \\
\hline \multicolumn{9}{|c|}{ Barotropic stream function (Sv) } \\
\hline \multicolumn{2}{|l|}{ whole basin } & 1.12 & 0.95 & 0.95 & 0.95 & 0.96 & 0.95 & 0.97 \\
\hline \multicolumn{2}{|l|}{ W Med } & 1.40 & 1.32 & 1.32 & 1.32 & 1.34 & 1.31 & 1.35 \\
\hline \multicolumn{2}{|l|}{ E Med } & 0.77 & 0.51 & 0.50 & 0.51 & 0.52 & 0.50 & 0.50 \\
\hline
\end{tabular}

cept during the winter in L1 (Fig. 4), where the error tends to decrease throughout the runs for all sampling strategies.

Sampling strategy T7 determines an error reduction of 15$20 \%$ for the whole Mediterranean Sea (Figs. 3-4). It is more effective in the western basin than in the eastern basin, in all seasons and layers. The difference is evident mainly in summer in L1 (Figs. 5a-6a), with 30\% error reduction in the western basin compared to $10 \%$ in the eastern basin, and in winter, in L1 and L2, with 30-35\% (west, Fig. 7a) compared to $20-25 \%$ (east, Fig. 8a). Taking this strategy as a reference, the comparative analysis of the various sampling strategies allows one to point out what follows.

Strategy T4 gives results which are close to T7 in L1 and L2 and close to the free run in L3 (Figs. 3-4), and this is expected because T4 XBTs cover only L1 and L2, while no data is assimilated in L3. However, a non-zero (although small) error reduction can also be seen in L3 and a corresponding error reduction decrease in L2 as a consequence of vertical exchanges related to model dynamics. This situation is observed both in summer and in winter.

Considering the whole Mediterranean basin, strategy AXT7 produces a larger impact than strategy T7, particularly in summer, when the maximum error reduction reaches $30-35 \%$ (Fig. 3). In winter, the error reduction is about $20 \%$ and the improvement relative to $\mathrm{T} 7$ is much smaller (Fig. 4). In all seasons in L2 and L3, the impact is maximum after 3 assimilation cycles (day 21, Figs. 3-4), when VOS XBTs are first introduced in the assimilation, and subsequently decreases, but still remains larger than for strategy T7. In L1, the maximum error reduction occurs much later, around day 55-60 in summer and at the end of the experiment in winter (Figs. 3-4). In the western basin, in summer, more than $35 \%$ 
a) West basin - summer - set $A$

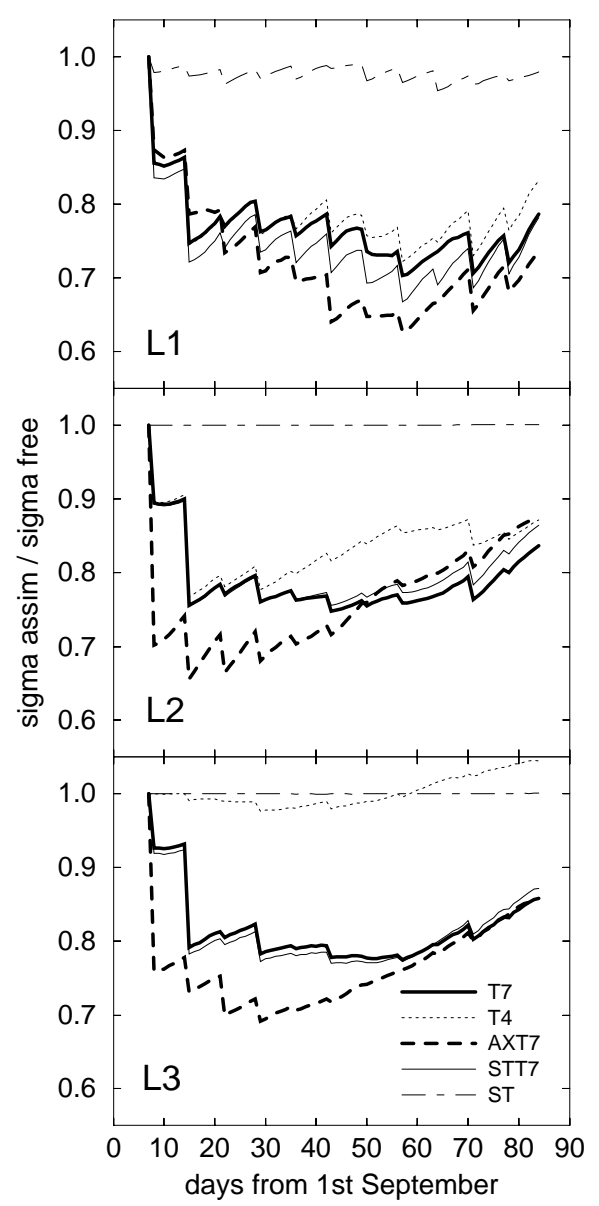

b) West basin - summer - set B

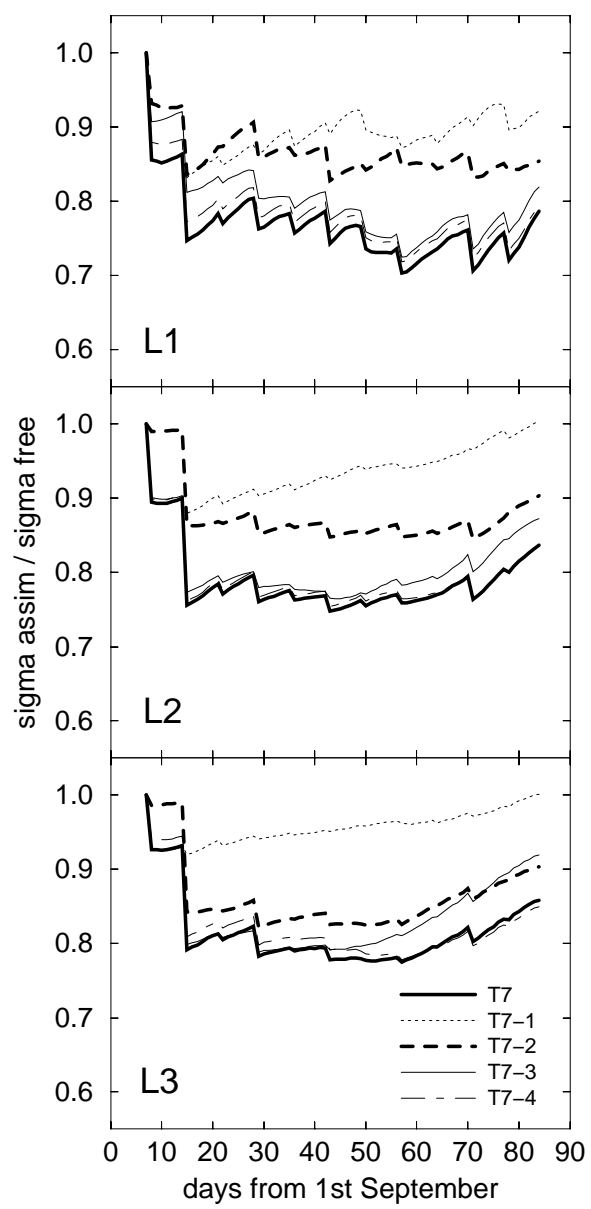

Fig. 5. Time series of temperature relative errors for the western basin in the summer OSSEs with sampling strategies of set A (a) and set B (b). L1 indicates the surface layer, L2 the intermediate layer and L3 the deep layer.

error reduction is reached in L1 around days 55-60 (Fig. 5a). In L2 and L3, a 30\% error reduction is obtained during the first weeks, while the error converges towards that of $\mathrm{T} 7 \mathrm{by}$ the end of the experiment (Fig. 5a). In winter, the impact of strategy AXT7 does not differ much from that of T7, except in L3 (Fig. 7a). In the eastern basin, the AXBTs produce a notable initial impact (Figs. 6a and 8a), with $20-25 \%$ error reduction after 2 weeks, and the assimilation of XBT data produce a further improvement during the subsequent 2-3 weeks, reaching a maximum of $35 \%$ error reduction in L2 (Figs. 6a and 8a) in all seasons. Later on, the improvement tends to converge to that of other sampling strategies. The large spatial coverage with temperature profiles makes AXT7 the most effective sampling strategy in all layers in summer, in the whole Mediterranean and the two subbasins (Figs. 3, $5 \mathrm{a}$ and $6 \mathrm{a}$ ), with up to $35 \%$ error reduction. In winter, AXT7 is again the best strategy in the eastern basin (Fig. 8a) and exhibits an intermediate performance between T7 and STT7 in the whole Mediterranean and western basins (Figs. 4a and 7a).

In the whole Mediterranean, strategy STT7 almost coin- cides with $\mathrm{T} 7$ in all layers in summer, while in winter, its impact is quite larger in all layers (Fig. 4). This seasonal behaviour can be related to the different vertical structures of the water column. In summer, the strong stratification limits the vertical exchanges and, therefore, prevents a significant impact of surface temperature, except to a few levels within $\mathrm{L} 1$, while, in winter, the absence of stratification and the occurrence of convection, induced by the atmospheric forcing, allows surface temperature to produce an impact also in the lower layers. The improvement achieved by strategy STT7, relative to $\mathrm{T} 7$, is partly related to the notably larger surface data coverage of the basin, but it should also be noted that the correct sea surface temperature is expected to improve the surface heat flux calculation, which represents a crucial element for convective deep water formation. In the western basin, in winter, strategy STT7 has a larger impact than T7, particularly in L2 and L3 (Fig. 7a), since convection and vertical mixing are very effective in that area and season. The error reduction reaches $30-40 \%$ and makes STT7 the most effective sampling strategy in the region in that season, as it occurs for the whole basin. In the eastern basin, STT7 es- 

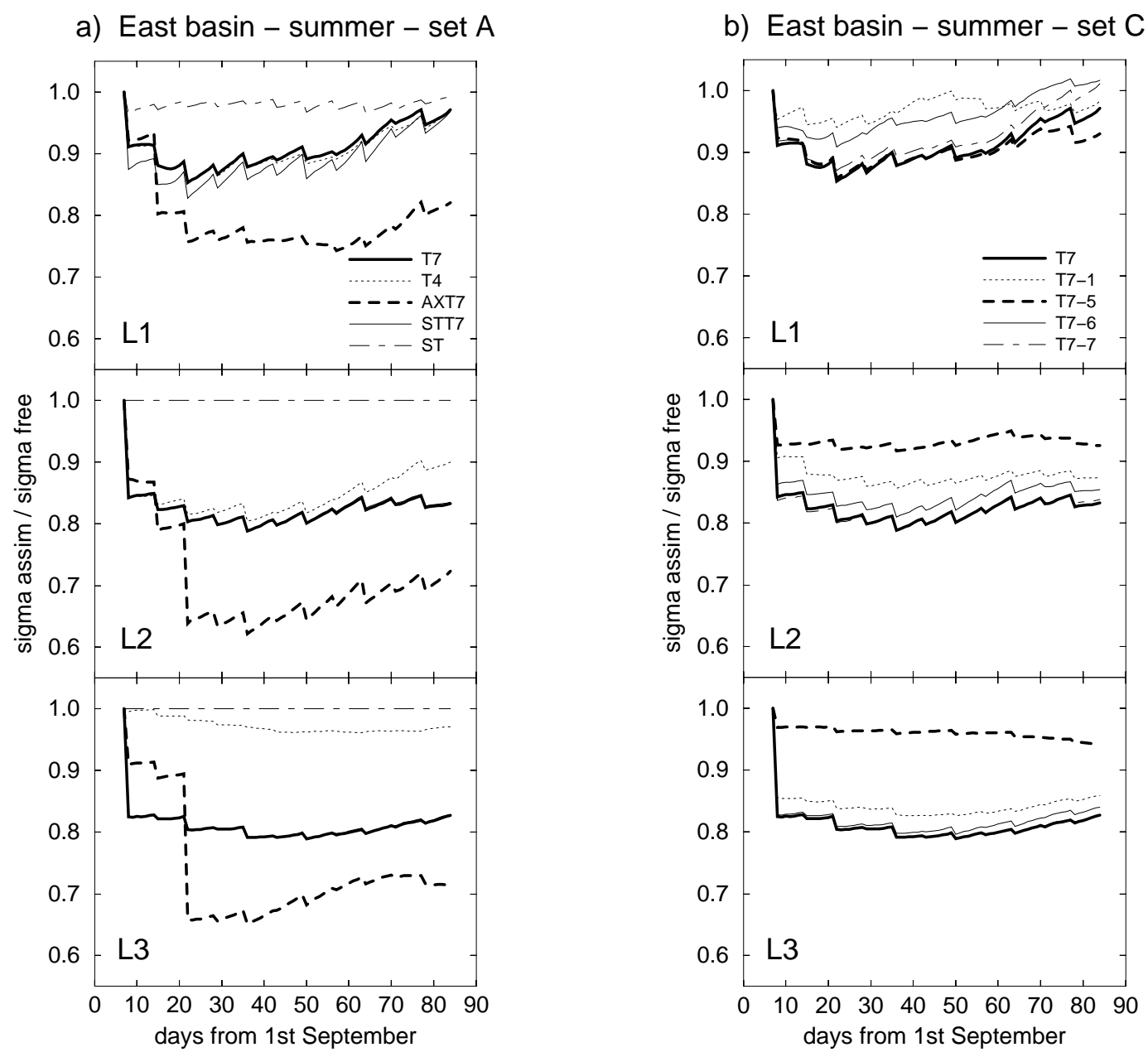

Fig. 6. Time series of temperature relative errors for the eastern basin in the summer OSSEs with sampling strategies of set A (a) and set C (b). L1 indicates the surface layer, L2 the intermediate layer and L3 the deep layer.

sentially coincides with $\mathrm{T} 7$ in all layers (Fig. 8a), as is the case of summer, when the impact of strategy STT7 is small or negligible in all layers (Figs. 5a-6a).

In the experiments made with sampling strategy ST (surface temperature only), the data impact is very small, with a maximum error reduction of less than $10 \%$ in L1 in winter (Figs. 4, 7a and 8a), while it is almost zero in all basins and seasons in L2 and L3. The same conclusion can be generally drawn also if strategies STT7 and T7 are compared, with the result that, if surface temperature is not assimilated, the error reduction loss is negligible everywhere in summer and in the intermediate and deep layers (L2 and L3) of the eastern basin in winter. The case of L2 and L3 in the western basin in winter represents a notable exception; in fact, the error reduction achieved with strategy STT7 is significantly greater than with strategy T7 (Figs. 4 and 7a), despite the fact that surface temperature assimilation alone has no impact on those layers. The probable reason is that the assimilation of temperature profiles allows for better control of the vertical processes (very active in winter in the western basin), which, in turn, enhances the transfer of information from the surface to the lower layers.

The impact of individual VOS tracks is assessed in the experiments with sampling strategies T7-n, where all tracks are used, except track " $n$ " (see Fig. 1). It is convenient to compare strategies T7-n to strategy T7 and examine the error reduction lost by removing each track. In the whole basin, the impact of track 1, analysed in the experiments with strategy T7-1, is notably smaller than that of T7 in all layers and seasons. Track 1 , in fact, provides a large number of temperature profiles in dynamically active regions, such as the Alboran Sea, Algerian Current region, the Ionian Sea and the Rhodes Gyre. Also, in the eastern Mediterranean, the impact of strategy T7-1 is always smaller than that of T7 in all seasons and layers (Figs. 6b and 8b). In the western Mediterranean, seasonal differences appear, since while in summer, the absence of track 1 produces a significantly lower impact than strategy T7, losing about $15 \%$ error reduction (Fig. 5 b), the active winter dynamics can effectively spread the information from tracks 2, 3 and 4 horizontally, thus partly compensating for the absence of track 1; this can be seen particularly in L1 (Fig. 7b), where T7-1 becomes very close to T7 (and 
a) West basin - winter - set $A$

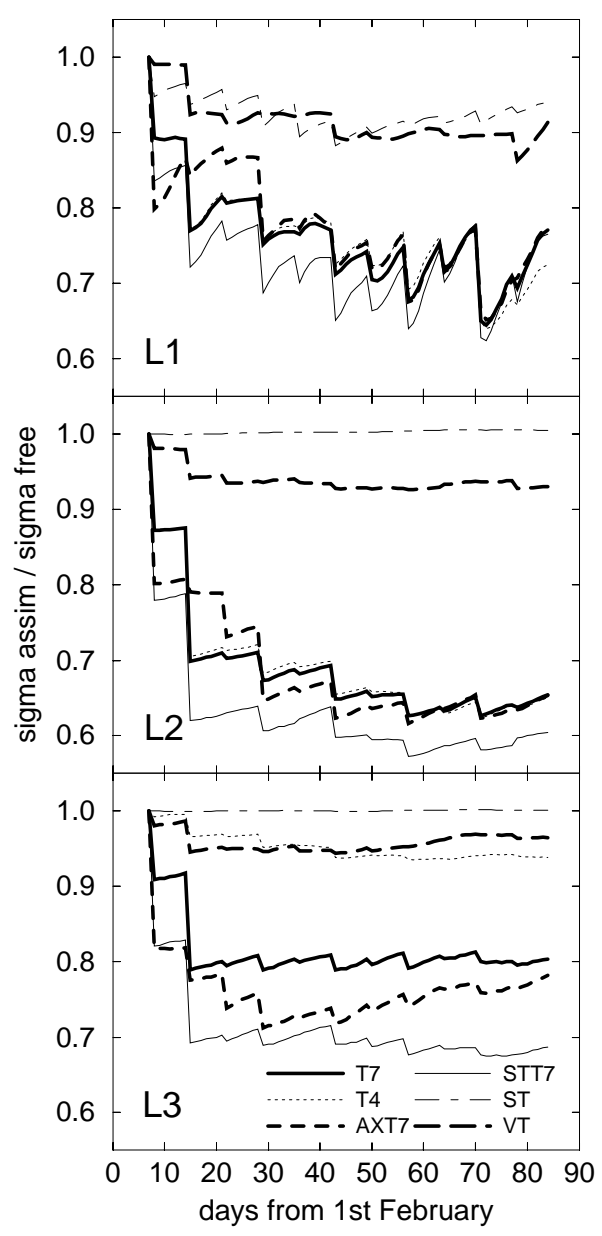

b) West basin - winter - set B

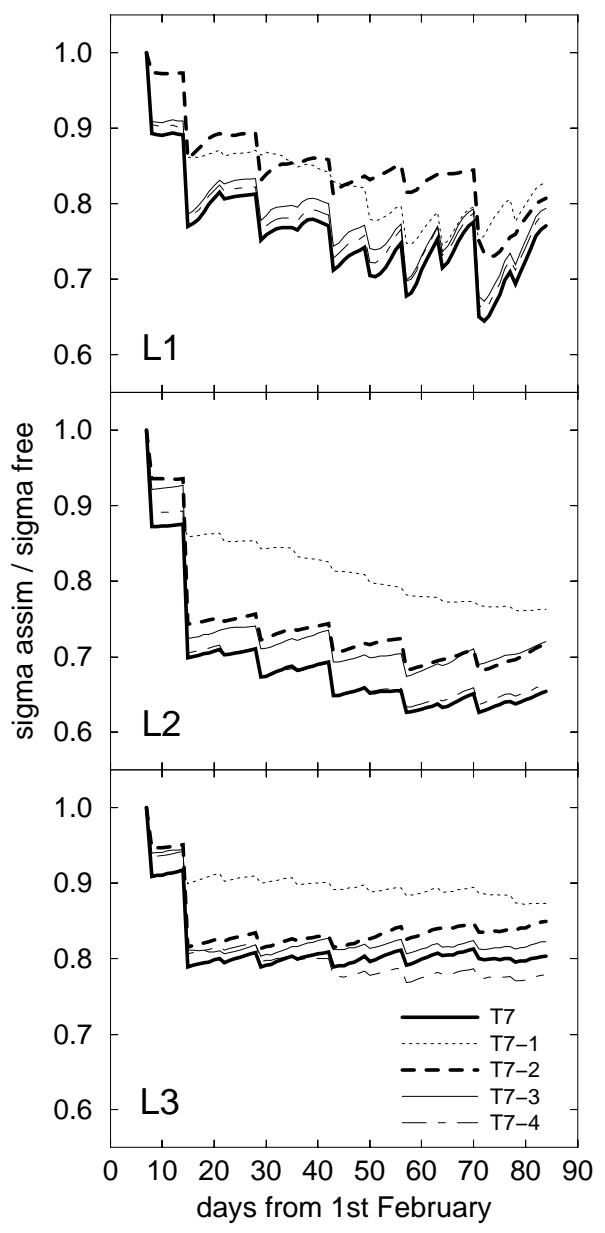

Fig. 7. As Fig. 5 for winter OSSEs.

the other sampling strategies, except VT) after 8 assimilation cycles (56 days). The inclusion of track 1 can also be seen as marked error reductions that occur every two assimilation cycles, after the odd cycles (e.g. L1 in Fig. 8b) in the eastern Mediterranean and after the even cycles (e.g. L1 in Fig. 7b) in the western Mediterranean.

The impact of the other tracks is observable in the respective subbasin, namely western for tracks $2-4$ and eastern for tracks 5-7, while in the opposite subbasin, it is negligible. In the western basin, sampling strategy T7-2 produces an error reduction loss of about $10 \%$ in $\mathrm{L} 1$ and $\mathrm{L} 2$, and $5 \%$ in $\mathrm{L} 3$ in all seasons (Figs. 5b and 7b); in winter, its impact is similar to that of strategy T7-1. T7-3 exhibits a small impact, with less than 5\% error reduction loss relative to $\mathrm{T} 7$. In the eastern basin, T7-5 has a significant impact in summer in L2 and L3, with 10 to $15 \%$ error reduction loss and a larger impact than T7-1 (Fig. 6b), while in winter, the impact is almost negligible (Fig. 8b). Sampling strategy T7-6 determines a 10\% error reduction loss in L1 in winter (Fig. 8b), and 5\% or less in the other layers, as well as in the whole water column in summer. Sampling strategies T7-4 and T7-7 virtually have no impact.

Strategy VT is studied only for winter and exhibits little impact, generally within $10 \%$ error reduction relative to the free run, due to the relatively low frequency of track coverage (see Table 3). Moreover, it should also be noted that the coverage of track 1 is practically negligible (only part of track $1 \mathrm{~b}$ is covered just in week 11), therefore losing a significant impact, as outlined above in the discussion for strategy T7-1.

A notable spatial variability in the error fields can be seen by looking at the maps shown in Figs. 9-10. They are computed for selected sampling strategies and consist of average absolute errors computed for every gridpoint over the last 9 weeks of each run (days 21-84), thus enabling one to recognize where and to what extent, on average, data assimilation produces an impact. The $70 \mathrm{~m}$ depth map is representative of the surface layer (L1) and the $320 \mathrm{~m}$ map represents the intermediate layer (L2). As expected, error reductions relative to the free run mainly occur close to the data positions. In summer (Fig. 9), improvements over the free run are observed for both T7 and AXT7 sampling strategies in all seasons and layers, particularly in the regions of Alboran Sea-Algerian 
a) East basin - winter - set A

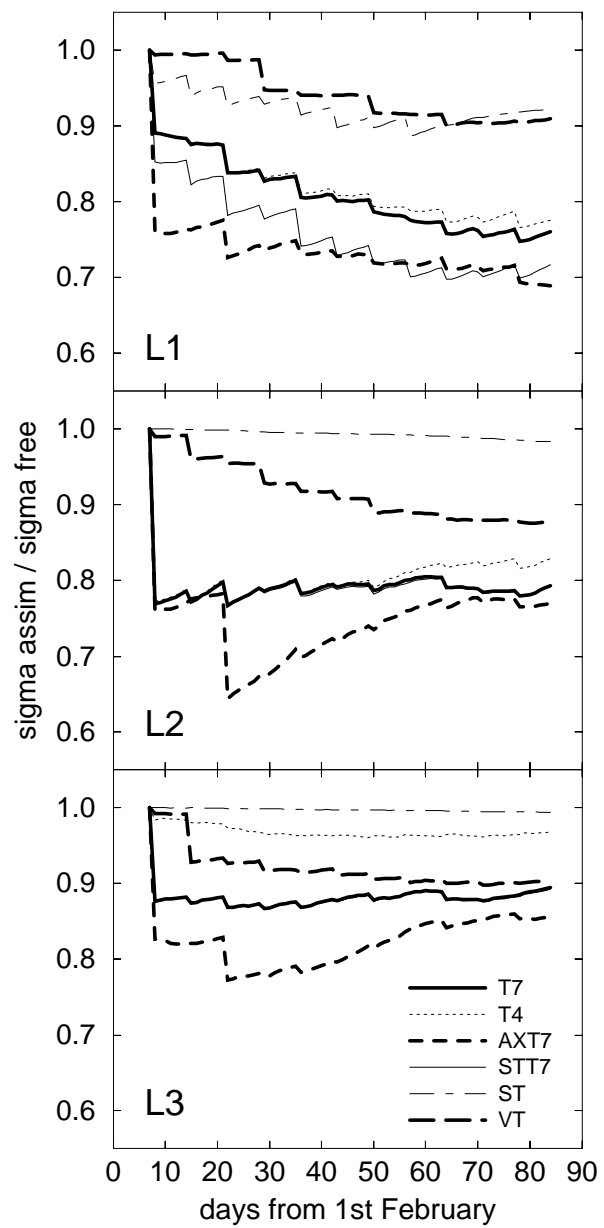

b) East basin - winter - set C

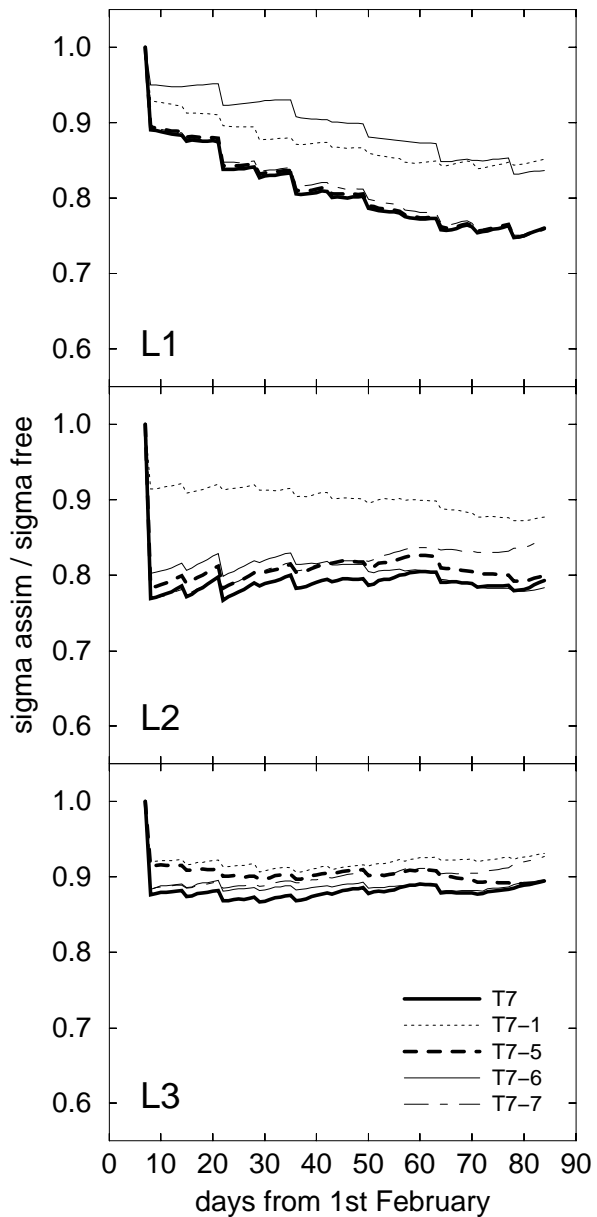

Fig. 8. As Fig. 6 for winter OSSEs.

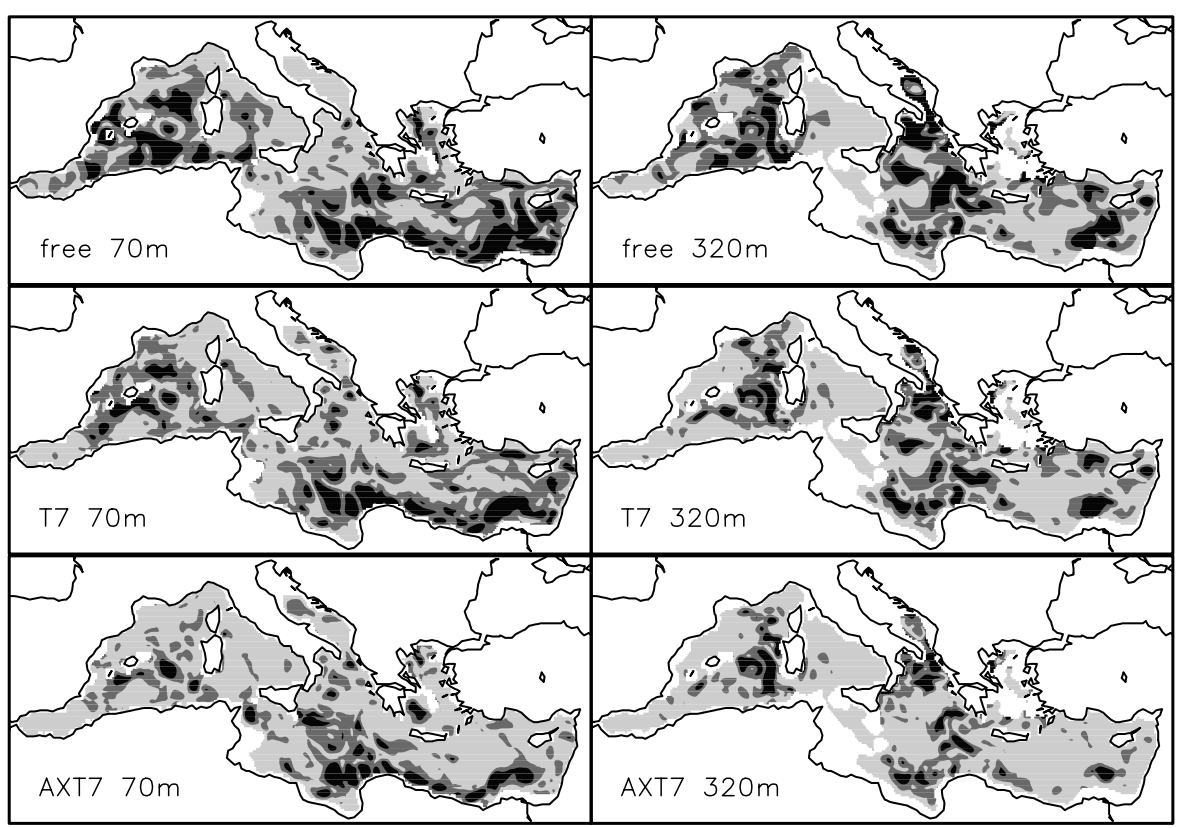

Fig. 9. Time-averaged (days 21-84) error in the summer OSSEs for selected sampling strategies and depths. Light grey corresponds to errors less than $0.5^{\circ} \mathrm{C}$ at $70 \mathrm{~m}$ depth and $0.1^{\circ} \mathrm{C}$ at $320 \mathrm{~m}$; black corresponds to errors greater than $1.0^{\circ} \mathrm{C}$ at $70 \mathrm{~m}$ depth and $0.2^{\circ} \mathrm{C}$ at $320 \mathrm{~m}$. 


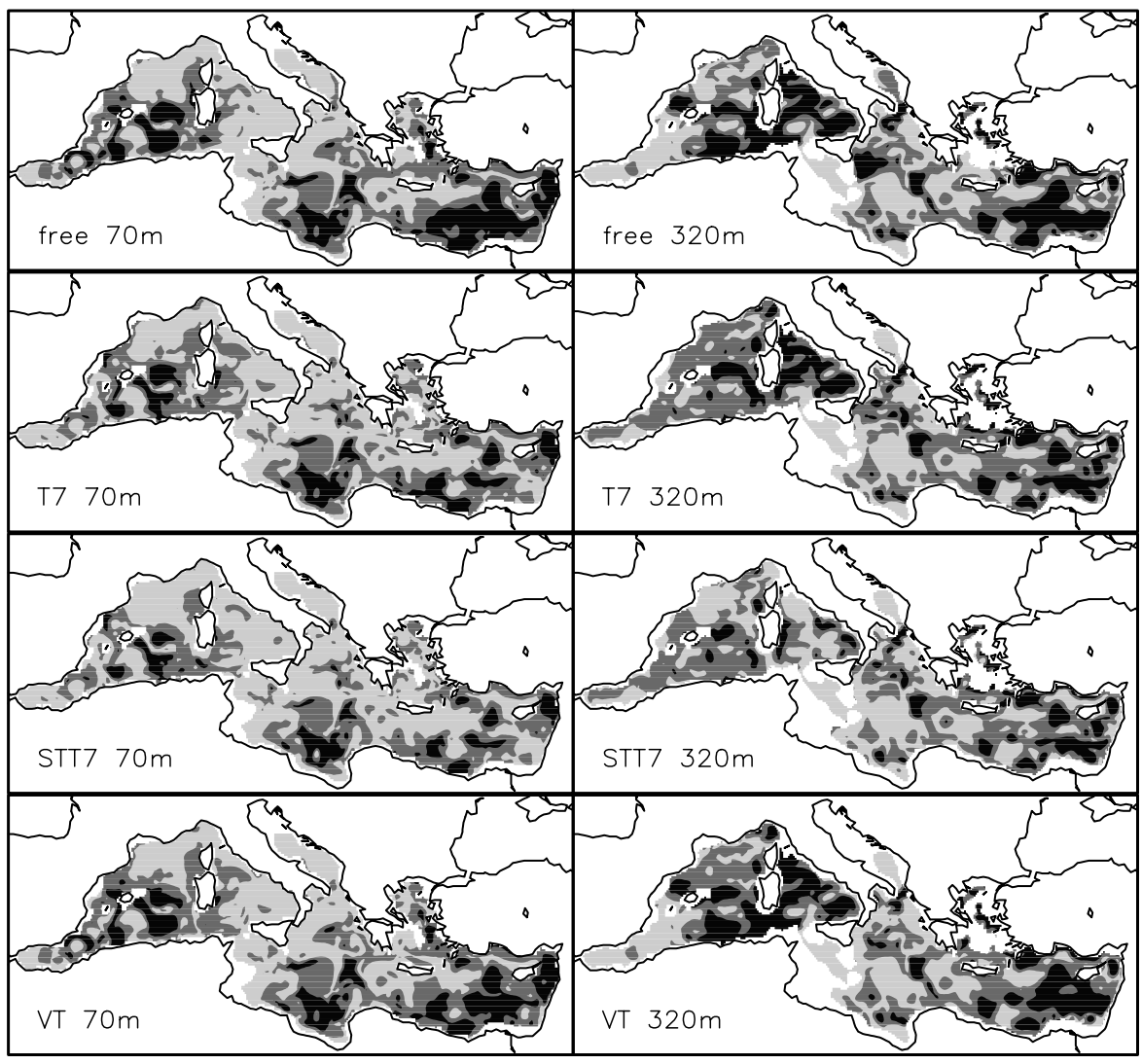

Fig. 10. Time-averaged (days 2184) error in the winter OSSEs for selected sampling strategies and depths. Light grey corresponds to errors less than $0.3^{\circ} \mathrm{C}$ at $70 \mathrm{~m}$ depth and $0.15^{\circ} \mathrm{C}$ at $320 \mathrm{~m}$; black corresponds to errors greater than $0.6^{\circ} \mathrm{C}$ at $70 \mathrm{~m}$ depth and $0.3^{\circ} \mathrm{C}$ at $320 \mathrm{~m}$.
Current and of the Liguro-Provençal-Catalan Current, in the western Mediterranean, and around Cyprus, in the eastern basin. Strategy AXT7 is also effective in the Rhodes Gyre area and the Ionian Sea. In winter (Fig. 10), in the western Mediterranean, both T7 and STT7 sampling strategies produce a general moderate improvement at $70 \mathrm{~m}$ depth, while at $320 \mathrm{~m}$ depth, the improvement is observed off the coast of Algeria and, with strategy STT7, in the Tyrrhenian Sea. In the eastern basin, notable improvements are mainly found in the Levantine Basin and, at $320 \mathrm{~m}$ depth, in the Ionian Sea, southeast of Sicily. In spite of general error decrease, however, local error increases appear in several cases, for instance, in the Sicily Channel at $70 \mathrm{~m}$ depth with strategy AXT7 (Fig. 9), and in winter in the western basin at $320 \mathrm{~m}$ depth with strategies T7 and STT7 (Fig. 10). The maps for VT sampling strategy (Fig. 10) clearly show that data sampling is insufficient over most of the basin to produce a significant error reduction relative to the free run.

\subsection{Salinity, density, stream function}

Salinity errors exhibit a general reduction in all layers, but the impact is smaller than for temperature and the impacts of the various sampling strategies cannot be distinguished well from each other. The error reduction is generally less than $10 \%$ and the largest value is $15 \%$, found in L3 in the western basin for strategy ST, which also gives the best results for temperature. Note that, at least for L1, the comparatively small impact can be partly explained by the fact that surface salinity is relaxed to climatological values, both in the free and assimilation runs.

Density is generally improved mainly as a consequence of temperature data assimilation. The error reduction is, however, lower than for temperature and the comparison of the different sampling strategies leads essentially to the same conclusions deduced from the analysis of temperature errors.

Concerning the barotropic stream function, the impact is small for all sampling strategies and all seasons, with less than $10 \%$ error reduction.

\section{Spatial impact}

From the discussion in the previous section it turns out that the basin circulation is expected to play a role in driving the information introduced in the model by data assimilation away from data positions. To explore this fact, experiments have been performed by assimilating isolated simulated temperature profiles and comparing the spatial patterns of their impact to features of the basin circulation.

The data impact $I$, as a function of time $t$, is defined as:

$$
I(t)=\left|\frac{A(t)-F(t)}{A\left(t_{0}\right)-C\left(t_{0}\right)}\right|,
$$



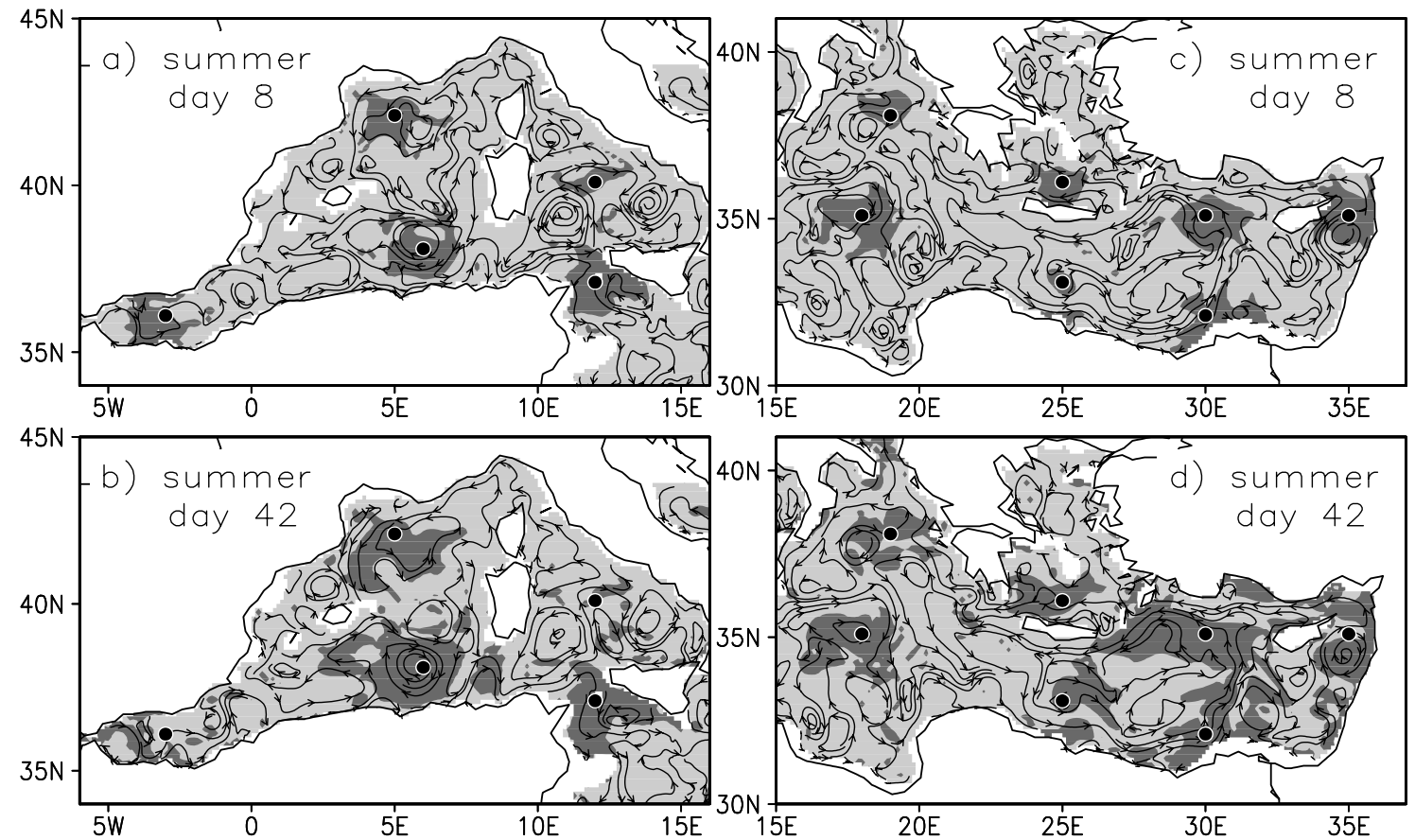

Fig. 11. Maps of data impact and basin circulation (streamlines) in the summer experiment at $50 \mathrm{~m}$ depth: western basin, day 8 (a) and day 42 (b); eastern basin, day 8 (c) and day 42 (d). The circulation shown is the average during the days 1-8 and 35-42, respectively. Dark grey indicates impact greater than 0.3 . Black dots indicate the data positions.

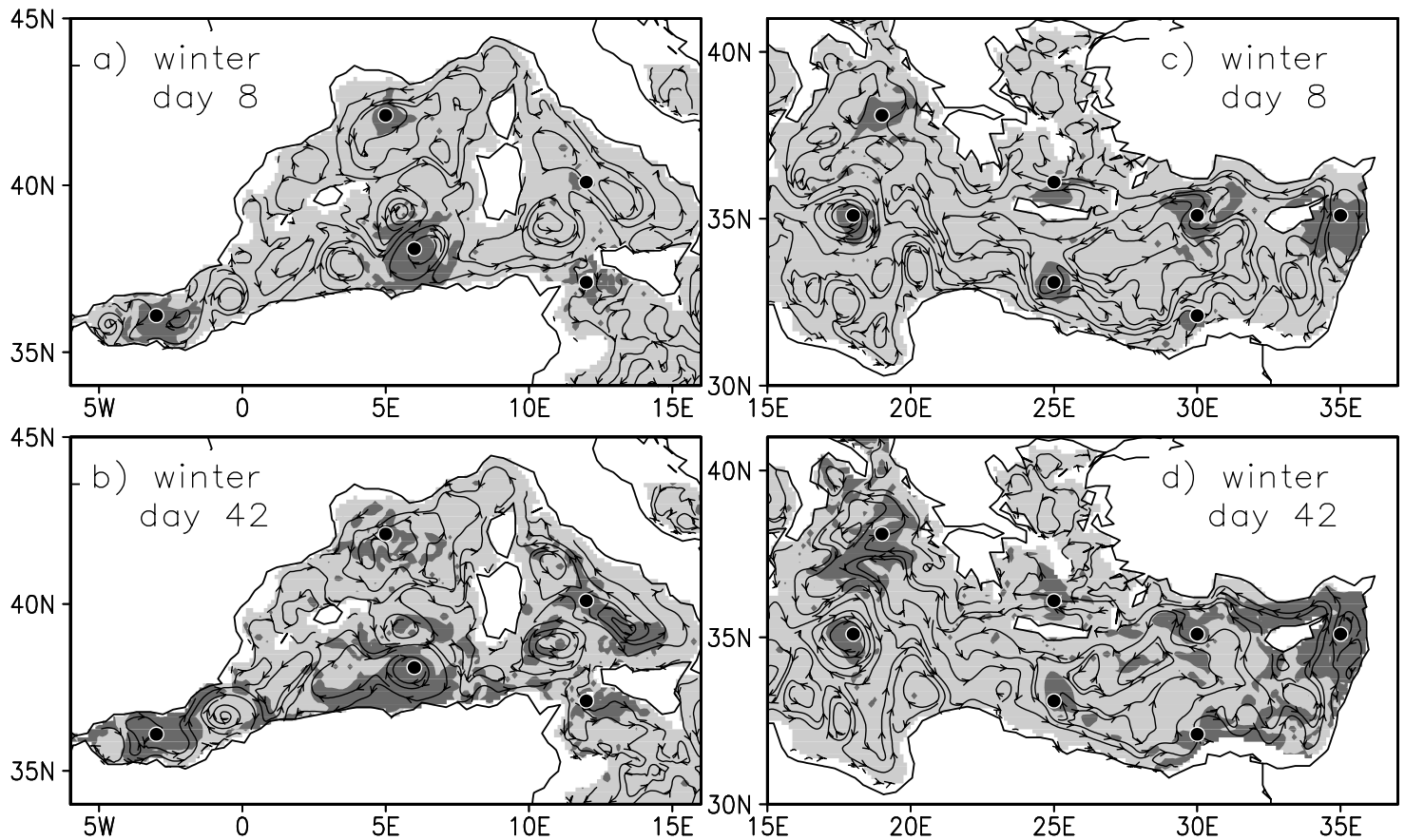

Fig. 12. Maps of data impact and basin circulation (streamlines) in the winter experiment at $50 \mathrm{~m}$ depth: western basin, day 8 (a) and day 42 (b); eastern basin, day 8 (c) and day 42 (d). The circulation shown is the average during the days 1-8 and 35-42, respectively. Dark grey indicates impact greater than 0.3 . Black dots indicate the data positions.

where $A$ is the field value in the assimilation run, $F$ in the free run and $C$ in the control run; $t_{0}$ is the time of initialization. The difference between assimilation and free runs quantify the "signal" introduced at the data position, while the difference between assimilation and control initial conditions serves as a normalizing factor to homogenize the visu- 
alization of results.

A total of 13 temperature profiles are positioned in the entire basin, far enough from each other to recognize the individual spatial impact patterns during the experiment. The profile positions are indicated by black dots in Figs. 11-12.

The runs are performed under similar conditions for the sampling strategies' assessment (see Sect. 2), with the differences being that profiles are assimilated once a day and that the experiments are carried out for 6 weeks. Figures 1112 illustrate the results of such experiments for summer and winter, respectively, by showing the superposition of "data impact" (as defined above) fields on day 8 (when the model is corrected for the first time) and day 42 (end of the experiment) on the mean current field during the previous week.

The data impact appears to be advected by the circulation and the role of the major currents can be recognized. In the western basin, the Algerian Current drives the data impact following the current meandering, and is more effective in winter (Fig. 12a-b). At intermediate depths $(320 \mathrm{~m}$, not shown), the current in the Alboran Sea is opposite than that found in the surface layer and the data impact is driven towards Gibraltar.

In the Levantine Basin, the large cyclonic gyre connected to the Mid-Mediterranean Jet and the Asia Minor Current (Figs. 11c-d, Figs.12c-d) is effective in merging the impact of the profiles in that region. By contrast, the impact of the profile inserted in the anticyclone of central Ionian appears trapped, particularly in winter (Figs. 12a-b), and cannot merge with that of the profile in the northern Ionian due to the Atlantic-Ionian Stream located in between.

\section{Summary and conclusion}

For the first time OSSEs have been performed in the Mediterranean Sea to investigate and compare the usefulness of different temperature sampling strategies, which are included in a Mediterranean operational observing system for forecasting purposes. The sampling strategy assessment has been made by means of twin experiments, in which the impact of data assimilation into a Mediterranean GCM is quantified as the error reduction is achieved in the assimilation runs relative to the free run. The OSSEs have been performed in summer and winter conditions, in order to recognize the seasonal influences on the impact of data assimilation, related to the different characteristics of the basin circulation. Several sampling strategies have been studied, most of which are based on the deployment of XBTs along the VOS tracks, forming the network shown in Fig. 1. Ten sampling strategies make use of XBT data only, with differences concerning the maximum profiles depth, the number of VOS tracks and the frequency of track coverage; among these, we include the actual sampling performed during the Targeted Operational Period in winter-spring 2000 (Demirov et al., 2003). Two sampling strategies also include additional data sets, namely AXBT profiles and sea surface temperatures, and one sampling strategy includes only surface temperature.
The impact of such sampling strategies achieves maximum error reductions between 20 and 35\%, depending on the season and the depth range along the water column. Effects of the basin dynamics can be recognized on the propagation of data impact, particularly in the western Mediterranean, where in winter, the circulation and vertical mixing allow sea surface temperature assimilation to significantly affect also the deep layer L3 (below $400 \mathrm{~m}$ ), and the absence of track 1 is partly compensated for in the surface layer L1 (above $240 \mathrm{~m}$ ) by the information coming from other tracks. The impact of individual VOS tracks, assessed as an error reduction loss relative to the T7 sampling strategy, depends on the track location and length; track 1 generally has the largest impact, but similar and even larger impacts are found in winter for track 2, in the western basin, and in summer for track 5 , in the eastern basin. The lack of data can be observed particularly in the VT sampling strategy, whose small impact is the direct consequence of the low frequency of the tracks' coverage. Two conclusions can be drawn from the VOS track network: 1) a significant improvement is achieved with a more frequent track coverage than that adopted in the TOP; 2) the highest impact is observed for track 1 , and, seasonally, for tracks 2 and 5; tracks 4 and 7 have almost no impact.

Sampling strategy AXT7 turns out to be the most effective in summer, in the whole Mediterranean, as well as in the western and eastern subbasins. In winter, strategy AXT7 has again the largest impact in the eastern Mediterranean, while STT7 performs best in the whole basin and in the western Mediterranean. Moreover, in the western basin, the simultaneous assimilation of XBT profiles and surface temperatures improves the model performance in the intermediate and lower layers more than with XBT profiles only, despite the fact that the impact of surface temperature alone is negligible in those layers. This allows one to conclude that under such conditions, the best result is achievable by the combination of a spatially limited vertical temperature coverage and a relatively wide surface coverage.

Qualitative results are obtained by comparing the basin circulation features and the spatial patterns of data impact, showing that the information introduced by data assimilation is essentially advected by the basin circulation.

This work has to be considered as a first step in the study of the impact of sampling strategies in the Mediterranean basin, particularly because only one variable (temperature) is taken into account both as the observed and the forecast parameter. In future work, the method outlined here will also be applied to the other prognostic variables and other observed variables (e.g. altimetry, current velocity), which are planned to be included in the Mediterranean observing system.

Acknowledgements. The authors would like to thank E. Demirov, N. Pinardi, P. De Mey and S. Sparnocchia for fruitful discussion and suggestions. G. M. R. Manzella (ENEA, La Spezia) provided the details of VT sampling strategy. The AVHRR weekly MCSST data coverage and related documentation are taken from the Physical Oceanography Data Active Archive Center at NASA Jet Propulsion Laboratory (podaac.jpl.nasa.gov). This work has been partly supported by the "Mediterranean Forecasting System Pilot Project", 
EC Contract MAS3-CT98-0171.

Topical Editor N. Pinardi thanks S. Pierini and another referee for their help in evaluating this paper.

\section{References}

Arnold, Jr., C. P. and Dey, C. H.: Observing-system simulation experiments: Past, present and future, Bull. Amer. Meteor. Soc., 67, 687-695, 1986.

Barth, N. and Wunsch, C.: Oceanographic experiment design by simulated annealing, J. Phys. Oceanogr., 20, 1249-1263, 1990.

Bennett, A. F.: Inverse methods for assessing ship-of-opportunity networks and estimating circulation and winds from tropical expendable bathythermograph data, J. Geophys. Res., 95, 1611116148, 1990.

Brasseur, P., Beckers, J. M., Brankart, J. M., and Schoenauen, R.: Seasonal temperature and salinity fields in the Mediterranean Sea: Climatological analyses of an historical data set, Deep-Sea Res., 43, 159-192, 1996.

De Mey, P.: Optimal interpolation in a model of the Azores current in 1986-1988, In: Data assimilation: Tools for modelling the ocean in a global perspective, NATO/ASI Series, I/19, (Eds) Brasseur, P. P. and Nihoul, J. C. J., Springer-Verlag, 253, 1994.

De Mey, P.: Data assimilation at the oceanic mesoscale: A Review, Special issue on "Data assimilation in meteorology and oceanography: Theory and practice", J. Met. Soc. Japan, 75, 415-427, 1997.

De Mey, P. and Benkiran, M.: A multivariate reduced-order optimal interpolation method and its application to the Mediterranean basin-scale circulation, In: Ocean Forecasting Conceptual Basis and Applications, (Eds) Pinardi, N. and Woods, J., Springer Verlag, 281-306, 2002.

Demirov, E., Pinardi, N., De Mey, P., Tonani, M., and Fratianni, C.: Assimilation scheme of Mediterranean Forecasting System: Operational implementation, Ann. Geophysicae, this issue, 2003.

Derber, J. and Rosati, A.: A global oceanic data assimilation scheme, J. Phys. Oceanogr., 19, 1333-1347, 1989.

Fichaut, M., Balopoulos, E., Dooley, H., Garcia-Fernandez, M.-J., Iona, A., Jourdan, D., Baudet, L., and Maillard, C.: A common protocol to assemble a coherent database from distributed heterogeneous data sets: The MEDATLAS data base experience,
In: Marine science and technology programme: Experiences in project data management, (Ed) Bohle-Carbonell, M., European Commission, Luxembourg, 349, 1998.

Hackert, E. C., Miller R. N., and Busalacchi, A. J.: An optimized design for a moored instrument array in the tropical Atlantic Ocean, J. Geophys. Res., 103, 7491-7509, 1998.

Hernandez, F., Le Traon, P.-Y., and Barth, N. H.: Optimizing a drifter cast strategy with a genetic algorithm, J. Atmos. Ocean. Tech., 12, 330-345, 1994.

Horton, C., Kerling, J., Athey, G., Schmitz, J., and Clifford, M.: Airborne expendable bathythermograph surveys of the eastern Mediterranean, J. Geophys. Res., 99, 9891-9905, 1994.

Kindle, J. C.: Sampling strategies and model assimilation of altimetric data for ocean monitoring and prediction, J. Geophys. Res., 91, 2418-2432, 1986.

Korres, G., Pinardi, N., and Lascaratos, A.: The ocean response to low-frequency interannual atmospheric variability in the Mediterranean Sea. Part I: sensitivity experiments and energy analysis, J. Climate, 13, 705-731, 2000.

MFS-VOS Group: The operational Ship of Opportunity program in the Mediterranean, Ann. Geophysicae, this issue, 2003.

Millot, C.: Circulation in the Western Mediterranean Sea, Oceanol. Acta, 10, 143-149, 1987.

Miyakoda, K., Smagorinsky, J., Strickler, R. F., and Hembree, G. D.: Experimental extended predictions with a nine-level hemispheric model, Mon. Wea. Rev., 97, 1-76, 1969.

Pacanowski, R. C., Dixon, K., and Rosati, A.: The GFDL Modular Ocean Model users guide, version 1.0, Geophysical Fluid Dynamics Laboratory Ocean Tech. Rep. 2, 18, 1990.

Pinardi, N., and Flemming, N. C. (Eds): The Mediterranean Forecasting System Science Plan, EuroGOOS Publication No. 11, Southampton Oceanographic Centre, Southampton, UK, 52, 1998.

Robinson, A. R., Golnaraghi, M., Leslie, W. G., Artegiani, A., Hecht, A., Lazzoni, E., Michelato, A., Sansone, E., Theocharis, A., and Ünlüata, Ü.: The eastern Mediterranean general circulation: features, structure and variability, Dyn. Atmos. Oceans, 15, 215-240, 1991.

Rohaly, G. D. and Krishnamurti, I. N.: An observing system simulation experiment for the Laser Atmospheric Wind Sounder (LAWS), J. Applied Meteor., 32, 1453-1471, 1993. 